Trauma Surgery \& Acute Care Open

\title{
Mucormycosis emboli: a rare cause of segmental bowel ischemia
}

\author{
Ioana Baiu, Lisa Marie Knowlton
}

General Surgery, Stanford University, Stanford, California, USA

\section{Correspondence to} Dr loana Baiu, General Surgery, Stanford University, Stanford, CA 94305, USA; ibaiu@ stanford.edu

Received 17 February 2019 Revised 19 March 2019 Accepted 21 March 2019 (c) Author(s) (or their employer(s)) 2019. Re-use permitted under CC BY-NC. No commercial re-use. See rights and permissions. Published by BMJ.

To cite: Baiu I, Knowlton LM. Trauma Surg Acute Care Open 2019:4:e00305.
The patient is a 34-year-old man with a history of primary refractory acute myeloblastic leukemia diagnosed 1 year prior, with multiple relapses. As rescue treatment, he underwent allogeneic bone marrow transplant from cord blood 27 days prior to surgical consult. His post-transplant course has been notable for delayed engraftment, prolonged severe neutropenia, resulting in vancomycin-resistant Enterococcus, Streptococcus viridans and Streptococcus mitis bacteremia for which he treated with tedizolid, cefepime, Flagyl and daptomycin per guidance from the Infectious Disease team. On the day of consultation, he developed acute abdominal pain, he was on filgrastim to promote hematopoiesis, and prophylaxis with acyclovir, Bactrim, and caspofungin as well as the above antibiotics for bacteremia. A second antifungal was not started due to the potential toxicity and data from prior infections that he had. On surgical evaluation, his examination was notable for fever to $38.2^{\circ} \mathrm{C}$, tachycardia to 155 basic metabolic panel, hypotension to $99 / 81$ and tachypnea to 36; he was ill appearing with a distended abdomen and localized peritonitis. His white cell count was $0.2 \times 10^{9} / \mathrm{L}$ with an absolute neutrophil count (ANC) of zero. Additionally, he was anemic with a hemoglobin of $7 \mathrm{~g} / \mathrm{L}$, thrombocytopenic with a platelet count of $10 \times 10^{9} / \mathrm{L}$, and a lactic acid of $3.1 \mathrm{mmol} / \mathrm{L}$. His CT scan earlier in the morning revealed segmental ischemia of the small bowel (figure 1).

\section{WHAT WOULD YOU DO?}

A. Offer non-operative management with broad spectrum antibiotics.

B. Transition to comfort care.

C. Perform a small bowel resection with primary anastomosis.

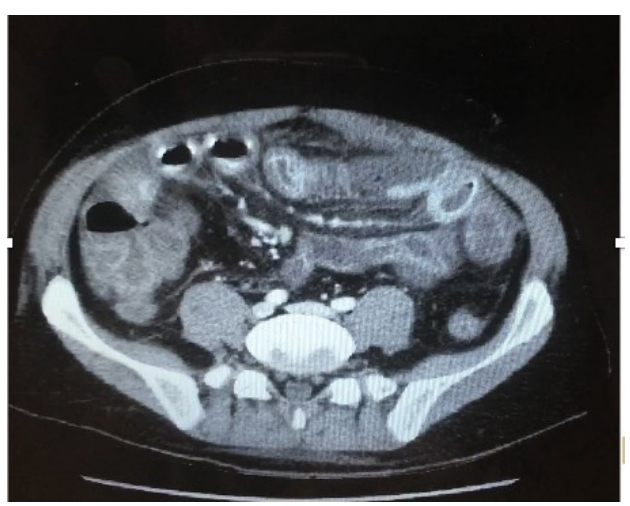

Figure 1 CT scan or initial presentation showing lack of wall enhancement of a discrete segment of small bowel.
D. Perform a small bowel resection with end ileostomy.

\section{WHAT WE DID AND WHY}

Correct answer: C

After discussion with the oncology team and the patient's family, the decision was made to proceed to the operating room for an exploratory laparotomy. A $15 \mathrm{~cm}$ ischemic bowel segment was identified without perforation (figure 2). Approximately 50 $\mathrm{cm}$ of small bowel was resected to achieve healthy margins and primary anastomosis was performed with a stapler device. The decision to create a primary anastomosis relied on the fact that the necrotic bowel was in the mid-jejunum and therefore an ileostomy would have been too proximal. Intraoperatively, he required norepinephrine and vasopressin for blood pressure support. A transesophageal echo was unremarkable. The patient was admitted to the intensive care unit overnight, pressors were weaned and he was extubated the following day. He was transferred to the floor and his diet was advanced on postoperative day (POD) 3 when he passed flatus. On POD 4, he was noted to have new fevers, with increased abdominal pain, lactic acidosis and respiratory decompensation. $\mathrm{He}$ continued to be neutropenic with white cell count of $0.1 \times 10^{9} / \mathrm{L}$ and ANC 0 . His lactic acid at that time was $3.7 \mathrm{mmol} / \mathrm{L}$. In the setting of acute worsening, amphotericin B (AmBisome) was started. Repeat CT scan showed an area of necrotic small bowel remote from the initial anastomosis created during his prior surgery. An expedited pathology report of the resected small bowel revealed invasive fungal forms in both the omental and small intestinal resection specimens, invading through blood vessel walls, with associated hemorrhage and transmural ischemic necrosis, consistent with mucormycosis (figure $3 \mathrm{~A}, \mathrm{~B}$ ). This finding confirmed that the source of his bowel ischemia was likely hematologic dissemination of mucormycosis with septic emboli. Amphotericin B was added to his antimicrobials. The risks of a repeat exploratory laparotomy and bowel resection were deemed quite high and the chances of cure were low. After further goals of care discussions with his family and the oncology team, the decision was made to proceed to comfort measures and the patient died the following day.

Mucormycosis is a type of fungus seen in immunocompromised patients with neutropenia, most commonly in those with an underlying hematologic condition and those with increased available serum iron. ${ }^{1} \mathrm{~A}$ hallmark of this infection is extensive angioinvasion with vessel thrombosis and 


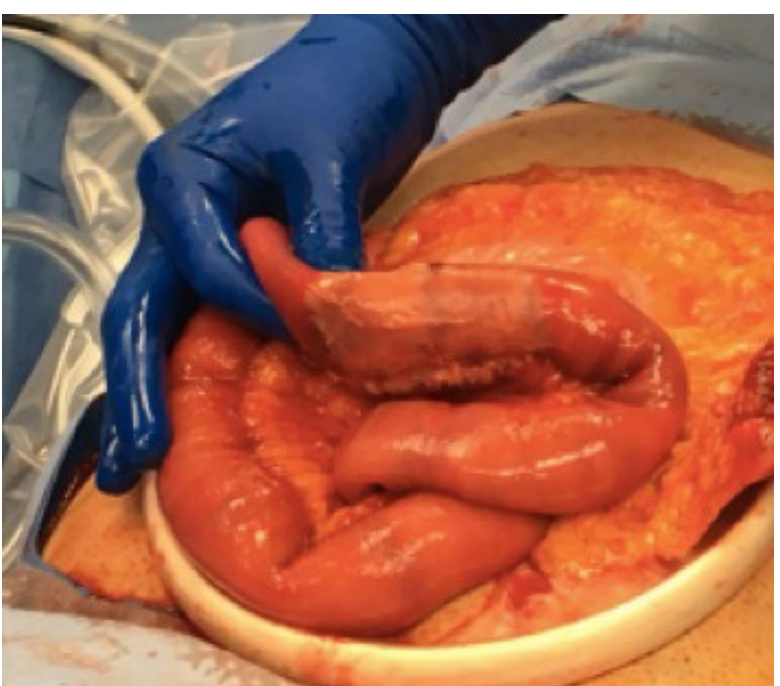

Figure 2 Intraoperative photo showing a well-demarcated segment of small bowel, concerning for a distal infected embolus.

tissue necrosis, which allows it to easily disseminate. Mucor infections can affect the rhinocerebral, pulmonary, cutaneous, gastrointestinal systems, or be disseminated. Only $2 \%$ to $11 \%$ of mucormycosis infections affect the gastrointestinal tract, and the majority of the time the colon is involved. ${ }^{2}$ Because the gastrointestinal infection of mucormycosis is often acute

\section{A}

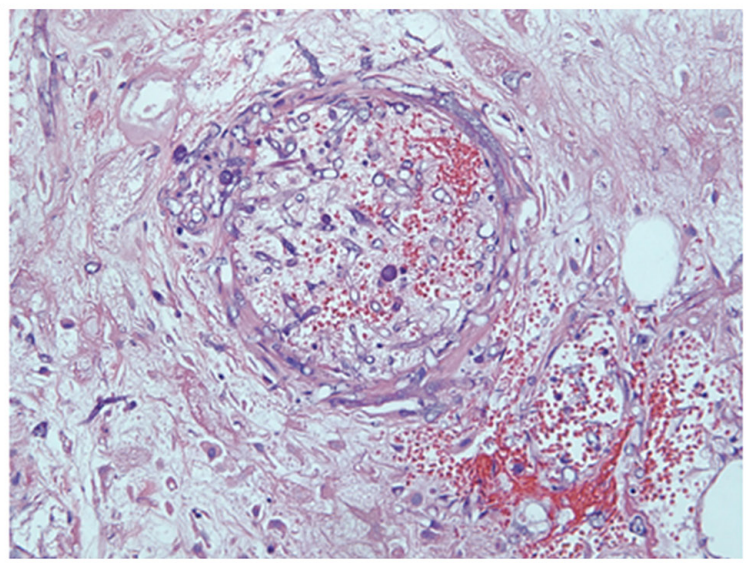

B

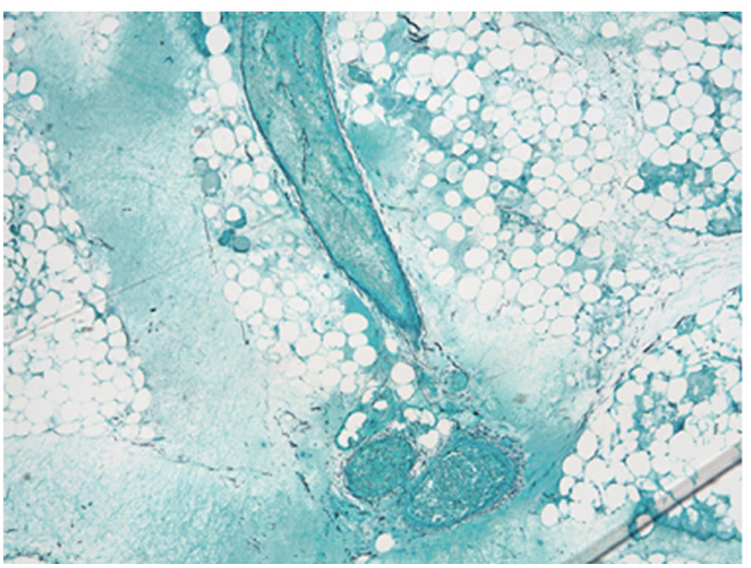

Figure 3 Microscopic slides showing findings consistent with mucormycosis. (A) angioinvasion, thrombosis, tissue necrosis; (B) fungal elements. and rapidly progressing, it is diagnosed most often post mortem. In fact, in some case series Mucor infection was diagnosed antemortem in only $9 \%$ of the cases, mostly in the rhino-orbito-cerebral and cutaneous systems (91\% to $100 \%)$ but $0 \%$ of the time in the gastrointestinal tract. ${ }^{3}$ The diagnosis of mucormycosis is difficult as it relies exclusively on culture and histopathology from the affected tissues. There are currently no serum fungal tests that can diagnose Mucor infections. Serum fungal assays such as 1,3-beta-D-glucan and Aspergillus galactomannan have no utility in Mucor because of its distinct characteristics. There are case reports describing a novel PCR that may allow for earlier detection of Mucor, but this is not yet widely available. ${ }^{4}$ The overall survival of patients with localized mucormycosis is $50 \%$, but disseminated infections have a mortality rate of nearly $100 \%$, worst in patients who underwent hematopoietic stem cell transplant. ${ }^{15}$ The treatment for mucormycosis is amphotericin B or amphotericin B lipid complex with caspofungin, and posaconazole can be used a second line. ${ }^{6}$ Caspofungin alone is not sufficient. Surgical debulking in patients with hematologic malignancies and gastrointestinal mucormycosis can have a significant effect on survival (50\% with surgery vs. $15 \%$ without). ${ }^{2}$ The timing of presentation can mimic typhlitis, in which case surgery would not be imminently indicated. Hemodynamic instability, however, should raise the suspicion and prompt physicians to consider mucormycosis as an etiology.

In retrospect, our patient's clinical presentation was consistent with mucormycosis. His acute presentation of left lower quadrant pain was distinct from what would be expected with typhlitis. Despite the fact that he underwent expeditious surgical resection of the affected small bowel with a rapid recovery, his antifungal coverage was not expanded to cover Mucor until POD 4 due to concern for drug toxicity. A higher degree of suspicion for disseminated mucormycosis infection might have promoted the early addition of amphotericin to his regimen. The expedited review of the resected bowel segment and the diagnosis of mucormycosis influenced downstream decisions to not proceed with a reoperation. We highlight this case because it represents a very rare cause of small bowel ischemia, where a high degree of suspicion is needed to make the diagnosis and accurately predict prognosis. Surgeons must be familiar with the implications of this infection so as to be able to advise patients and families about management, treatment options and prognosis.

Contributors IB is the surgical resident involved in this case and the first author. She wrote the draft. LMK is the Assistant Professor of Surgery and the attending surgeon on the case who reviewed the article.

Funding The authors have not declared a specific grant for this research from any funding agency in the public, commercial or not-for-profit sectors.

Competing interests None declared.

Patient consent for publication Not required.

Provenance and peer review Not commissioned; externally peer reviewed

Open access This is an open access article distributed in accordance with the Creative Commons Attribution Non Commercial (CC BY-NC 4.0) license, which permits others to distribute, remix, adapt, build upon this work non-commercially, and license their derivative works on different terms, provided the original work is properly cited, appropriate credit is given, any changes made indicated, and the use is non-commercial. See: http://creativecommons.org/licenses/by-nc/4.0/.

\section{REFERENCES}

1. Spellberg B, Edwards J, Ibrahim A. Novel perspectives on mucormycosis: pathophysiology, presentation, and management. Clin Microbiol Rev 2005; 18:556-69. 
2. Forrester JD, Chandra V, Shelton AA, Weiser TG. Gastrointestinal mucormycosis requiring surgery in adults with hematologic malignant tumors: literature review. Surg Infect 2015;16:194-202.

3. Prabhu RM, Patel R. Mucormycosis and entomophthoramycosis: a review of the clinical manifestations, diagnosis and treatment. Clin Microbiol Infect 2004;10 Suppl 1:31-47.

4. Hammond SP, Bialek R, Milner DA, Petschnigg EM, Baden LR, Marty FM. Molecular methods to improve diagnosis and identification of mucormycosis. J Clin Microbiol 2011:49:2151-3
5. Spellberg B, Walsh TJ, Kontoyiannis DP, Edwards J, Ibrahim AS. Recent advances in the management of mucormycosis: from bench to bedside. Clin Infect Dis 2009; $48: 1743-51$.

6. Skiada A, Lanternier F, Groll AH, Pagano L, Zimmerli S, Herbrecht R, Lortholary O, Petrikkos GL. European Conference on Infections in Leukemia. Diagnosis and treatment of mucormycosis in patients with hematological malignancies: guidelines from the 3rd European Conference on infections in leukemia (ECIL 3). Haematologica 2013;98:492-504.

7. Kontoyiannis DP, Lewis RE. How I treat mucormycosis. Blood 2011;118:1216-24. 